\title{
Narrativa
}

narrativa

Nuova serie

Letteratura e economia nell'Italia degli anni Duemila

\section{Emma SCHIAVON, Dentro la guerra. Le italiane dal 1915 al 1918}

\section{Eline Batsleer}

\section{OpenEdition}

\section{Journals}

Edizione digitale

URL: https://journals.openedition.org/narrativa/315

DOI: $10.4000 /$ narrativa.315

ISSN: 2804-1224

\section{Editore}

Presses universitaires de Paris Nanterre

\section{Edizione cartacea}

Data di pubblicazione: 1 décembre 2020

Paginazione: 199-200

ISBN: 978-2-84016-381-7

ISSN: 1166-3243

\section{Notizia bibliografica digitale}

Eline Batsleer, «Emma scHIAvon, Dentro la guerra. Le italiane dal 1915 al 1918», Narrativa [Online], 42 | 2020, online dal 01 novembre 2021, consultato il 08 décembre 2021. URL: http:// journals.openedition.org/narrativa/315 ; DOI: https://doi.org/10.4000/narrativa.315

Questo documento è stato generato automaticamente il 8 décembre 2021.

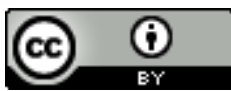

Narrativa est mise à disposition selon les termes de la Licence Creative Commons Attribution 4.0 International. 


\title{
Emma SCHIAVON, Dentro la guerra. Le italiane dal 1915 al 1918
}

\author{
Eline Batsleer
}

\section{NOTIZIA}

Emma SCHIAVON, Dentro la guerra. Le italiane dal 1915 al 1918, Milano, Mondadori

Education, 2018, pp. 213.

1 Il libro di Emma Schiavon, pubblicato nella collana Dentro la storia diretta da Fulvio Cammarano, è il secondo volume della studiosa dedicato alla donna nella Grande Guerra. Nell'introduzione viene spiegato come la Grande Guerra comporta una maggiore responsabilità per le donne che diventano le protagoniste del cosiddetto fronte interno. Nonostante il ruolo cruciale svolto dalle donne durante il conflitto, Schiavon osserva che storicamente la Grande Guerra è stata considerata un'esperienza esclusivamente maschile, motivo per cui il punto di vista femminile è a lungo stato escluso dalla ricerca, nonché dalla memoria del conflitto. Il volume propone una sintesi complessiva degli studi più recenti dedicati al tema e tuttavia la studiosa sottolinea, giustamente, che la ricerca si trova ancora in una fase iniziale. La prima parte dello studio si sofferma sull'atteggiamento delle donne nei confronti del conflitto, in relazione alle rispettive classi sociali. Secondo Schiavon l'idea che le donne siano di natura contrarie alla guerra - idea tradizionalmente associata all'istinto materno - è errata. Al contrario, il primo conflitto mondiale permette alle donne, per la prima volta, di lasciarsi alle spalle il focolare domestico e di assumere un nuovo ruolo nella società, determinando un cambiamento radicale per cui "le donne non erano più umili creature che vivevano nell'orbita della famiglia: erano entrate nel mondo del lavoro e costituivano un elemento dinamico della società" (p. 105). Attraverso lo studio dei diversi ruoli assunti dalle donne, ai quali dedica sempre un capitolo a sé stante, Schiavon dimostra che le donne non rimangono estranee al conflitto, anzi, si adattano alla nuova situazione e non esitano a esprimere le loro posizioni e insoddisfazioni, per esempio durante le proteste contadine, alle quali parteciparono con determinazione. 
Nella seconda parte del libro l'attenzione si sposta verso alcune figure simboliche che, come enunciato dal sottotitolo, si collocano a metà strada "tra immaginario e realtà". Si pensi in primo luogo alle infermiere, ovvero le cosiddette "bianche sorelle", ma anche alle madrine (che intrattenevano corrispondenze con i soldati al fronte) o alle prostitute, che venivano accusate non solo di pratiche immorali, ma persino di spionaggio. Altrettanta attenzione è dedicata alle vittime della guerra, ossia le madri e le vedove, nonché le profughe e le donne che sono state vittime di violenza sessuale. Al dibattito sugli stupri di guerra è dedicato un breve capitolo in cui viene spiegato come il tema della violenza contro le donne e la conseguente maternità forzata siano diventate un'arma fondamentale della propaganda anti-tedesca. In sintesi, basandosi su un'ampia e ricca bibliografia, Schiavon fornisce un quadro complessivo e dettagliato del ruolo assunto dalle italiane nella Grande Guerra e il suo studio offre senza dubbio nuovi spunti di riflessione e di ricerca. 